\title{
The Study on Stylistic Features of Public Speaking
}

\author{
Li Chunying \\ The College of Post and Telecommunication of WIT \\ Wuhan, Hubei 430073, China \\ E-mail address:88507566@qq.com
}

\begin{abstract}
Public speaking is a kind of literature stylistic, which includes plenty of specific categories, such as the public speech, preachment of the religion and the public lecture given by the university teachers. A successful public speech owns tremendous social functions and interpersonal meanings. Though various speeches are different from each other, there are still a lot of common points between them. This paper mainly studies the stylistic characteristics of public speaking on six aspects, they are: the use of modal verb, the use of personal pronoun, the use of simile and metaphor, the use of parallelism, the use of repetition and tense of sentences. By enumerating and analyzing successful speeches, this paper aims to offer a source of reference and guidance for lecturers and relevant scholars who are engaged in the study of this field, so as to attain the goal of delivering successful speeches.
\end{abstract}

Keywords—public speech; stylistics; feature; globalization

\section{INTRODUCTION}

Public speaking, as the name suggests, is the presentation form applied by social members for publicizing or instigation. ${ }^{[1]}$ Nowadays, public speaking has taken many forms. It can be such a large scale that held by countries in deliberating over economic or political issues, or it can be in a small scope that organized by civil groups or individuals, such as business presentations, speech contests or lectures on different aspects of life. Since public speaking is not an individual behavior, instead, it has strong sociality, logicality and direction. Public speaking can be divided into testimony and persuasion, on the basis of which, it can achieve other effects and impressions by getting various accesses to stylistics. ${ }^{[2]}$ Entering new century, public speech is playing a critical role in people's life as a communication mode. In political area, public speech is the most familiar way for politicians to give publicities of their views and stands. Likewise, in our common people's life, public speech is also prevalent involving entertainment, arts, technology, health, environment and so on, especially in our career field, public speech has been regarded as an indispensable living skill. ${ }^{[3]}$ Being possessed with excellent speaking ability can contribute to one's influence and social life to a large extent. Nowadays, it is not rare to find that a tremendous majority of lecturers are eloquent. They can speak volubly and distinguish themselves in each professional stage, so as to act a substantial role in society. Besides boasting outstanding eloquences, some lecturers who are talented in literature speak refined words just like lotus flowers blooming on lips; some are precisely wording with emotional depths and using well-created rhetorical devices. In their speeches, there is no shred of tediousness and monotonousness which attracts the audience deeply. This is exactly where the art of public speech lies.

\section{STYLISTIC FEATURES}

\section{A. The Use of Modal Verb}

In public speaking, modal verbs are not simply verbs; they stand for the possibilities of some events, or their resolution for changes and improvements, or even their doubts about the feasibilities. ${ }^{[4]}$ The most commonly used modal verbs in public speaking are: can, may, must, should and their anamorphosis. Basically, "can" shows ability, "may" shows permission, "must" shows determination and "will" shows achieving goals. From cognitive perspective, "can" and "may" show possibilities; "must" shows the possibility of conjecture; "shall" and "will" show the future actions and resolutions. Although in communication, these definitions can cause ambiguities; these modal words can appear in public speaking for the lecturers to express their urgencies, wishes or determinations.

The following words are from Clinton's farewell speech, from which we can obviously feel the strong emotion "must" conveys:

"We must work harder to overcome our differences. In our hearts and in our laws, we must treat all our people with fairness and dignity, regardless of their race, religion, gender or sexual orientation and regardless of when they arrived in our country". (Extracts from Clinton's farewell speech, 2001)

In the above sentences, "must" appeared twice. On the one hand, it shows the president's confidence in his people and his determinations in overcoming difficulties with his fellow citizens even though the fact that he would no longer be the president any more. On the other hand, it can appeal to the audience in a great degree because of the stressing role it plays.

\section{B. The Use of Personal Pronoun}

Usually, in public speaking, pronouns can be weighty signals showing the language skills of lecturers. In Annan's Speech at Tsinghua University, 2004 the statistics of the use of different personal pronouns is shown in the following chart: 
TABLE I. Personal Pronouns Statistics in AnNAN's SPEeCH

\begin{tabular}{|c|c|c|}
\hline $\begin{array}{c}\text { personal } \\
\text { pronouns }\end{array}$ & number & percentage \\
\hline I & 15 & $20.3 \%$ \\
\hline my & 4 & $5.4 \%$ \\
\hline you / your & 32 & $43.2 \%$ \\
\hline It & 19 & $25.7 \%$ \\
\hline those & 4 & $5.4 \%$ \\
\hline
\end{tabular}

"You", "we" can shorten the distance between the lecturer and the audience to a great extent as if it's a personal talk, which conveys the expectation and hope the lecturer delivers. The third personal pronoun "it", "those" is much more objective than the use of "we" and "you". When the lecturer uses "I" for many times, there can be two situations. The first is that he or she is telling the feelings at present or about a story occurred to him or her, which makes the audience concern about what's exactly going on. The second is that the speaker intends to stress the conclusion that can be essential and should not be neglected, especially in political speeches.

In this speech, we can find that the use of "you" and "your" takes a percentage of 43.2. Since it is a speech to university students, "you" can shorten the distance between the lecturer and the audience to a great extent as if it's a personal talk, which conveys the expectation and hope the lecturer delivers.

(1) Increasingly, your economy depends on exchanges with other countries - both imports and exports, of both goods and capital. Foreign investment plays an essential role in your growth, while your holdings of foreign currencies - and your management of your own currency - are coming to play a vital part in the international monetary system. (Annan's Speech at Tsinghua University, 2004)

Moreover, the use of "you" in most cases denotes the audience or the mass group they stands for, which can be applied in a large scope. Such as the following extract:

(2) You guys at Eliot House, give yourselves a nice round of applause because you had the head lice scare this year, and it shut you down for most last semester. But you did not mind the tents they set up for you and you were just troopers. You really were. (Extract from Class Day Speech June 4, 2003 by Will Ferrell)

In the above extract, the lecturer uses "you" to refer to himself actually. This can better offer the audience the imagination of the environment of that time.

\section{The Use of Simile and Metaphor}

Simile is a direct, expressed comparison between two things essentially unlike, but resembling each other in at least one aspect. By using of simile, the audience can have an imaginary expectation of their future when their dreams come true by the leader, which decorates the speech to a large extent.

Ross gives a rather free translation: "metaphor consists in giving the thing a name that belongs to something else." (1475) Some scholars (Li Fuyin, 1999; Bussmann, 2000; Leezenberg,
2001) proposed that, there are mainly three approaches to metaphor studies, namely, the semantic approach, the pragmatic approach and the conceptualist approach.

Here is an example: Now is the time to rise from the dark and desolate valley of segregation to the sunlit path of racial justice. Now is the time to open the doors of opportunity to all if God's children. Now is the time to lift our nation from the quicksand of racial injustice to the solid rock of brotherhood. (I Have A Dream by Martin Luther King, 1963)

From the extract, the lecturer gives the audience his urgency for a better world with racial justice and walking out the dark valley, which gives the audience all his fight and struggle, inspiring the audience a lot.

\section{The Use of Parallelism}

From rhetorical perspective, figure of balance identified by a similarity in the syntactical structure of a set of words in successive phrases, clauses, sentences; successive words, phrases, clauses with the same or very similar grammatical structure. ${ }^{[5]}$ In expressing and communication, parallelism can strengthen its vigor and stringency. The structure can be prepositional phrases, words, subordinate clauses and so on. In public speaking, parataxis is made of three or more clauses and they are related. By using parallelism, speaking can be fluent and of brio. In the following extract:

Let us embrace those responsibilities and possibilities; let us share them "knit together...as one"; let us take up the work joyfully, for such an assignment is a privilege beyond measure. (Happiness Is a Journey, Not a Destination by Thomas Friedman, 2005)

The parallelism with repeated words "let us" fully shows the lecturer's determination and outlook for future, conveying the lecturer's point that enjoying the process really matters in one's way of pursuing dreams.

\section{E. The Use of Repetition}

Repetition in speeches is often neglected because of the negative impression we have on it. Li Hongmei (2010) pointed out that functions of repetition include repetition for emphasis, repetition for clarity, repetition for rhythm. Repetition can balance sentences and highlight the key points.

Proper repetition of key points is acceptable and can be used as a means of emphasis. Usually, such repetition often combines with parallelism, containing a serious of words, phrases, clauses and so on. In this way, the audience can better feel how forceful the speech delivered to them. To emphasize the meaning of certain contents by repeating one word or phrase can place them deeply in the audience's mind and display strong emotion.

For example, let us resist the temptation to fall back on the same partisanship and pettiness and immaturity that have poisoned our politics for so long. (Extract from Obama's Victory Speech, 2012)

The similar initial sound [p] of partisanship, pettiness, poisoned and politics can be uttered with force that appealed for the audience to take actions. 


\section{F. Sense of Sentences}

Public speaking relates to various tenses of sentences according to the context and time. On the one hand, lecturers sometimes need to look back on some experiences in their lives that might have paved the way for his or her present success or achievements, or maybe they need to tell a story that inspired them once. On the other hand, they may express thanks, regrets and some other moods, or show his or her determination and promise. Therefore, it's quite common to find that the tense of sentences in public speaking vary from situation to situation. From political speech, we often find that they used to have to bear in mind the current situation, focus on the future and review the past. And it's similar in other speeches on dissimilar topics. While, the present tense takes a large part in general public speaking, especially the political speaking to stress the age characteristics and themes. Here is an extract from Obama's inaugural address:

"We, the people, still believe that enduring security and lasting peace do not require perpetual war. Our brave men and women in uniform, tempered by the flames of battle, are unmatched in skill and courage. Our citizens, seared by the memory of those we have lost, know too well the price that is paid for liberty. The knowledge of their sacrifice will keep us forever vigilant against those who would do us harm. But we are also heirs to those who won the peace and not just the war, who turned sworn enemies into the surest of friends, and we must carry those lessons into this time as well." (Extract from Obama's Inaugural Address, 2013)

In the above extract, the present tense is applied in the whole paragraph, since political speaking are objective and aims to tell the truth. Obama refers to the people's endeavor in enduring security and peace for this country, including some real cases happened on those soldiers and citizens. In this part, Obama declares the facts and expresses his appreciation and admiration to those people.

\section{CONCLUSIONS}

Public speaking is quite different from other kinds of communication in that it involves a definite intention. The content of public speech is also different from daily conversations. In the process of speaking, the speaker must put forward a large amount of points and evidence to convince his or her audience (Chen Jing 2012). Public speaking acts as a bridge that connected each other from all walks of life.
Practically, the study of stylistic features in public speaking can benefit individuals personally, professionally and socially. ${ }^{[6]}$ Firstly, from making a study of stylistics, it can help people acquire necessary basic features relating to stylistics, which could be unfamiliar in our daily communications; secondly, it can cultivate people's ability to appreciate the art of public speaking; finally, public speaking can promote people's role in society and enhance their contacts with others both in community and in career.

Though this thesis reaches some conclusions in the study of stylistics on public speaking, there are still many limitations. Firstly, there can be many perspectives related to successful speeches, but the paper just studied the use of modal verb, the use of personal pronoun, the use of simile and metaphor, and the use of parallelism, the use of repetition and tense of sentences. Other ways of analyzing public speaking like strategies, interpersonal meaning of modal verbs and so on can be adopted in further study. Secondly, not much data are collected for the research, instead the paper chose to enumerate extracts as examples to clarify the points. Since public speaking relating to many levels, as the paper mentioned in the beginning, like business speeches, political speeches, technological speeches and many other fields. It's hard to ensure the exact data of the applications of stylistic features. Thirdly, because of the author's limited knowledge, there can be inevitably subjective thoughts or misunderstandings in the study. It will be complemented in later work and study. The author suggests that more data should be collected for the analysis of the use of stylistic features in public speaking, which could be more persuasive.

\section{REFERENCES}

[1] Aussure, F.D. Course in General Linguistics[M]. Beijing: Beijing Foreign Language Teaching and Research Press, 1983.

[2] Alliday M.A.K. An Introduction to Functional Grammar [M]. London: Edward, 1985/1994

[3] Simpson, P. Language Ideology and Point of View [M]. London/New York: Routeldge, 1993.

[4] THOMPSON,G . Introducing Functional Grammar [M]. Beijing Foreign Language Teaching and Research Press 2000.

[5] Shouhua Qi. The Art of Public Speaking in English [M].Shanghai Education Press, 2004

[6] Shuzheng Zhang. Introduction to Linguistics [M]. Wuhan:Wuhan University Press, 2012 . 